\title{
ALLAH TRINITARIS DALAM REFLEKSI JOHN ZIZIOULAS
}

\author{
YAP Fu LAN*
}

\begin{abstract}
Abstrak: John Zizioulas merefleksikan kembali doktrin Allah Trinitaris dan mencoba mencari cara-cara baru menolong umat beriman zaman ini menemukan makna ajaran iman ini. Merujuk teologi para Bapa Gereja Kapadokia, Zizioulas mengajukan gambar Allah Trinitaris sebagai Pribadi yang berkomunitas. Pribadi memiliki tiga karakteristik: primer dan absolut, ekstasis dan hipostasis, unik dan tak tergantikan. Pribadi selalu bergerak ke luar dirinya, ke arah pribadi yang lain, maka ia menerima keberbedaan. Kehidupan dan identitas otentik pribadi ditemukan hanya di dalam komunitas yang dibangunnya bersama pribadi-pribadi yang lain. Gerak Pribadi Allah adalah eros, cinta yang merangkul pribadipribadi yang lain beserta keberbedaan mereka, yakni manusia dan segenap ciptaan. Berkomunitas dengan Allah dan segenap ciptaan, manusia melampaui substansi manusiawi dan kondisi naturalnya. Manusia tidak lagi menjadi milik kematian melainkan kehidupan kekal. Gereja adalah image Allah Trinitaris karena ia adalah komunitas pribadipribadi yang mengalami kelahiran baru oleh Roh Kudus di dalam peristiwa Kristus. Sebagai image Allah Trinitaris, cara Gereja hadir di dunia ialah dengan menjadi komunitas katolik dan ekaristis. Untuk menjadi komunitas katolik-ekaristis, pembaruan cara hidup, struktur hirarkis, dan pelayanan Gereja adalah sebuah kebutuhan.
\end{abstract}

Kata-kata Kunci: Pribadi, substansi, ekstasis-hipostasis, keberbedaan, identitas otentik, komunitas ekaristis, imago Dei/Trinitatis, eros.

Abstract: John Zizioulas reflects on the doctrine of the Trinity in order to find new ways that may help the faithful to grasp the meaning of this teaching. Referring to the theology of Cappadocian Fathers, Zizioulas

* Yap Fu Lan, Program Studi Ilmu Pendidikan Teologi, Fakultas Keguruan dan Ilmu Pendidikan, Universitas Katolik Indonesia Atma Jaya, Jl. Jend. Sudirman 51, Jakarta 12930.E-mail:vayful@gmail.com. 
provides a picture of the Trinity as Persons within communion. A person has three primary characteristics: primary and absolute, ecstatic and hypostatic, unique and irreplaceable. A person always moves towards others, thus embracing otherness. The very life and authentic identity of a person can be found only in communion with others. The Person of God moves as eros, God's love which embraces the others and otherness, i.e. human beings and the rest of creation. Being in communion with God and all creations, the human being over-comes the human substance and its nature. The human being no longer belongs to death but to eternal life. The church is an image of the Trinity for it is a communion of new persons that are reborn in the Holy Spirit within the Christ event. As the image of the Trinity, the Church's way of being in this world is by becoming a catholic and eucharistic community. To be such a community, the Churh needs a hierarchical structure, and ministries a renewal of life.

Keywords: Person, substance, ecstatic-hypostatic, otherness, authentic identity, eucharistic community, image of God/image of the Trinity, eros.

\section{PENDAHULUAN}

Allah Trinitaris adalah doktrin iman yang rumusannya sering diserukan umat Kristiani di dalam syahadat, doa, dan ibadat. Namun, dari masa ke masa, doktrin iman ini merupakan topik perbincangan yang sulit bagi umat awam, dan bahan perdebatan yang tak kunjung selesai bagi para teolog. Berbagai uraian sistematik dan metafora digunakan untuk memberikan penjelasan yang memadai (dalam arti 'memuaskan akal') tentang satu Allah tiga Pribadi. Belakangan ini, para teolog kontem-porer sadar bahwa upaya mencari ulasan logis tentang doktrin Allah Trinitaris telah memudarkan makna ajaran imannya bagi hidup Kristiani. Kesadaran ini menggerakkan mereka untuk menggunakan pendekatan reflektif. ${ }^{1}$

1 Untuk mendapatkan wawasan mengenai berbagai pandangan para teolog kontemporer dari Eropa, Amerika Utara, Amerika Latin, Asia, dan Afrika mengenai Allah Trinitaris, pembaca dapat menyimak hasil studi Veli-Matti Kärkkäinen dalam The Trinity: Global Perspectives (Louisville - London: Westminster John Knox Press, 2007). Kärkkäinen menyajikannya pada bagian ketiga buku ini, setelah ia menguraikan dasar biblis dan historis mengenai doktrin Allah Trinitaris. 
Seorang dari antara mereka ialah John Zizioulas, dari Gereja Ortodoks Yunani. ${ }^{2}$ Di dalam karya terbaiknya, Being as Communion (1985), Zizioulas menggambarkan Allah Trinitaris sebagai Pribadi yang berelasi dengan "yang lain," yang berada di luar Diri-Nya, yang berbeda dari Diri-Nya. Allah Trinitaris dapat dikenal hanya melalui relasi dan cinta personal. ${ }^{3}$ Uraian Zizioulas yang lebih komprehensif mengenai Allah Trinitaris terdapat di dalam karyanya, Communion and Otherness, Further Studies in Personhood and the Church. ${ }^{4}$ Karya ini, yang terbit setelah Being as Communion, memuat elemen-elemen inti teologi Zizioulas, yakni komunitas, keberbedaan ${ }^{5}$ (otherness), dan keberadaan diri sebagai pribadi (personhood), mencakup diri sendiri (self) dan pribadi yang lain (the other/others dan the Other).

Zizioulas mengundang kita untuk memandang gambar Allah Trinitaris yang berbeda, yang bernuansa gagasan teologis Gereja Timur, seraya merenungkan kembali identitas Gereja dan cara hidup Gereja dengan identitas itu. Refleksinya sangat padat dengan ide-ide teologis, kristologis, pneumatologis, dan eklesiologis dari kekayaan Gereja Timur maupun Gereja Barat. Karena berbagai keterbatasan, penulis hanya dapat mengangkat sebagian gagasan reflektif Zizioulas, dengan fokus pada ide "pribadi" yang dikenakan pada gambar Allah Trinitaris dan identitas Gereja. Paparan yang singkat ini akan penulis awali dengan uraian tesis dasar dan asal-usul gagasan teologis Zizioulas. Pada bagian

2 John Zizioulas, yang dikenal sebagai the Metropolitan John of Pergamon, lahir pada 10 Januari 1931.

3 Lih. John Zizioulas, Being as Communion: Studies in Personhood and the Church (Crestwood, NY: St. Vladimir's Seminary Press, 1985), pp. 15-16.

4 John Zizioulas, Communion and Otherness: Further Studies in Personhood and the Church, ed. Paul McPartlan (New York: T\&T Clark International, 2006).

5 Di dalam Kamus Besar Bahasa Indonesia hanya terdapat kata benda "perbedaan," yang didefinisikan sebagai "perihal yang membuat berbeda" (lih. Kamus Besar Bahasa Indonesia Dalam Jaringan, http:// bahasa.kemdiknas.go.id/kbbi/index.php. Diunduh pada 3 Maret, 2014). Namun bagi penulis kata "keberbedaan" lebih tepat digunakan sebagai terjemahan otherness. "Keberbedaan" menggambarkan kualitas menjadi yang berbeda atau menjadi yang lain. Meskipun tidak dimuat di dalam Kamus, kata "keberbedaan" sudah digunakan di dalam berbagai publikasi. 
penutup, penulis mencoba mengartikulasikan pesan dari refleksi Zizioulas di dalam konteks Gereja saat ini.

\section{TIDAK ADA PRIBADI TANPA KOMUNITAS}

Sebenarnya, tesis Zizioulas sederhana: "[t]here is no true being without communion. Nothing exists as an "individual," conceivable in itself. Communion is an ontological category." ${ }^{6}$ Tesis ini mengingatkan kita pada eskpresi puitis John Donne (1572-1631), No Man is an Island; tidak ada makhluk yang dapat hidup dan berkembang bila ia terisolasi dari lingkungan sekitarnya. Di dalam gagasan Zizioulas, tidak ada pribadi tanpa komunitas, dan tidak ada keduanya tanpa keberbedaan. Tesis ini merupakan kritik Zizioulas terhadap individualisme yang bertumbuh-kembang di Barat. Individualisme pada dasarnya menciptakan pertentangan antara komunitas dan keberbedaan. Di dalam individualisme terdapat keyakinan bahwa orang lain dan keberbedaannya merupakan ancaman. ${ }^{8}$

Meskipun Zizioulas menunjuk individualisme dan budaya Barat, ia sadar bahwa ketakutan pada keberbedaan dan kehadiran "yang lain," ada di dalam diri setiap orang yang hidup di belahan bumi mana pun. ${ }^{9}$ Keberbedaan seringkali menjadi dasar penolakan dan penerimaan di dalam interaksi sosial, dan mudah dimanipulasi demi konflik dan perpecahan. Berbagai indikator terlihat di dalam hidup harian kita, mulai dari penerapan prinsip like-or-dislike, suka-atau-tidak-suka kepada seseorang atau sekelompok orang, hingga diskriminasi rasial, bahkan pemusnahan suatu suku bangsa (genocide). Zizioulas menyatakan, penolakan

6 John Zizioulas, Being as Communion, p. 18.

7 Puisi ini merupakan bagian karya Donne, Meditation XVII dalam Devotions upon Emergent Occasions (1624). Biografi dan karya Donne dapat diakses melalui link: http:/ / www.poemhunter.com/john-donne/biography/. Diunduh pada 20 Agustus 2014.

8 Menurut Zizioulas, pemikiran Jean Paul Sartre merupakan cikal bakal individualisme; dan gagasan-gagasan Boethius (pribadi sebagai substansi individual yang rasional) dan Agustinus (kesadaran diri pribadi) adalah penopangnya. Lih. Zizioulas, Communion and Otherness, pp. 1, 45.

9 John Zizioulas, Communion and Otherness, p. 2. 
terhadap keberbedaan, diskriminasi, konflik, dan perpecahan adalah manifestasi-manifestasi kematian kekal. ${ }^{10}$

Tesis teologis Zizioulas bersumber dari teologi yang dikembangkan oleh tiga Bapa Gereja dari Kapadokia, Asia Kecil. Mereka adalah Basilius Agung, Gregorius dari Nyssa, dan Gregorius dari Naziansuz. Teologi para Bapa Gereja Kapadokia ini bersifat apologetik, menanggapi ajaran-ajaran Sabellius dan Eunomius (abad II). Sabellius mengajarkan bahwa Bapa, Putera, dan Roh Kudus bukan tiga Pribadi melainkan hanya tiga aspek atau tiga peran Allah. Menurutnya, hanya ada satu Pribadi Allah sedangkan Eunomius menolak keilahian Putera dengan argumen bahwa Allah tidak dilahirkan. ${ }^{11}$

Zizioulas memandang dua kekhasan di dalam gagasan para Bapa Gereja Kapadokia dibandingkan dengan pemikiran teologis para Bapa Gereja Yunani umumnya. Menurut ketiga Bapa Kapadokia, di dalam konteks Allah Trinitaris, hipostasis tidak berasosiasi dengan substansi (ousia), melainkan dengan person atau pribadi, dan substansi tidak melampaui pribadi, melainkan sebaliknya; pribadi melampaui substansi. ${ }^{12}$

Mengadopsi ide mengenai "pribadi" dari pemikiran ketiga Bapa Gereja tersebut, Zizioulas menjelaskan bahwa pribadi memiliki tiga karakter, yakni primer dan absolut, ekstasis dan hipostasis, unik dan tak tergantikan. Pribadi bersifat primer dan absolut sebab ia diciptakan oleh kebebasan. Sebagai yang primer dan absolut, pribadi memiliki otoritas di dalam dirinya, maka ia tidak dapat dikuasai oleh otoritas atau kekuasaan apapun di luar dirinya, entah alam, entah agama, entah moral, entah ideologi. ${ }^{13}$ Dengan kata lain, pribadi ada atau hadir bukan karena kebutuhan atau kehendak suatu otoritas demi tujuan tertentu, melainkan karena

10 John Zizioulas, Communion and Otherness, pp. 2-3.

11 John Zizioulas, Communion and Otherness, pp. 156-161.

12 John Zizioulas, Communion and Otherness, pp. 158, 159. Untuk mempelajari lebih lanjut terminologi yang digunakan Zizioulas beserta latar belakangnya, pembaca dapat melihat tulisan John G.F. Wilks, "The Trinitarian Ontology of John Zizioulas," dalam Vex evangelica 25 (1995): 63-88.

13 John Zizioulas, Communion and Otherness, pp. 99-112; 166. 
dan demi kebebasan. Pribadi tidak hadir untuk dirinya sendiri dan tidak bersifat eksklusif. Karakter ekstasis membuat pribadi selalu bergerak ke arah pribadi yang lain untuk membangun relasi dengan yang lain. Pribadi adalah a relational being, makhluk hidup yang berelasi. Dengan karakter ini, konsep kebebasan yang melekat pada pribadi adalah "bebas untuk" (free for), bukan "bebas dari" (free from).

Pada saat yang sama, karakter hipostasis menyatakan identitas pribadi sebagai the other bagi pribadi yang lain. Maka, ia menjadi unik dan—oleh sebab itu—keberadaannya tak tergantikan. Keunikan pribadi nampak karena ia berelasi dengan yang lain, bukan karena ia diklasifikasi atau dikelompokkan berdasarkan kualitas tertentu oleh otoritas atau kekuasaan di luar dirinya. ${ }^{14}$ Keunikan merekatkan sebuah identitas personal pada pribadi. Identitas personal membedakan pribadi yang satu dari pribadi yang lain, namun tidak menciptakan keterpisahan, diskriminasi, penolakan, atau perpecahan di antara mereka. Identitas personal justru menggerakkan pribadi untuk berelasi dengan yang lain. ${ }^{15}$ Sebab, ditegaskan oleh Zizioulas, "[p]ersonal identity is totally lost if isolated, for its ontological condition is relationship."16

Doktrin Allah Trinitaris, menurut Zizioulas, mengandung pengajaran bahwa keberbedaan dan komunitas terikat di dalam kesatuan ontologis. Keberbedaan dan keberadaan pribadi yang lain bukan konsekuensi apalagi ancaman bagi komunitas, melainkan kondisi atau syarat komunitas. Keberbedaan bersifat absolut sebagai kualitas yang membedakan pribadi yang satu dari pribadi yang lain. Keberbedaan satu pribadi tidak akan nampak apabila pribadi itu terisolasi. Hanya di dalam relasi, pribadi itu dikenali dan diakui oleh pribadi-pribadi yang lain. Bagi Zizioulas, Allah Trinitaris merupakan model pribadi dan relasi ini. ${ }^{17}$

14 John Zizioulas, Communion and Otherness, pp. 111-112; 167-168.

15 John Zizioulas, Communion and Otherness, p. 166.

16 John Zizioulas, Communion and Otherness, p. 112.

17 John Zizioulas, Communion and Otherness, pp. 4-5. 


\section{ALLAH TRINITARIS SEBAGAI PRIBADI YANG BERKOMUNITAS}

Mengikuti pemikiran para Bapa Gereja Kapadokia, Zizioulas pun menyatakan bahwa di dalam Allah Trinitaris ada substansi ilahi dan tiga Pribadi (Bapa, Putera, dan Roh Kudus). Substansi ilahi tidak mendahului atau menyebabkan ketiga Pribadi. Substansi ilahi mendasari pengakuan bahwa Allah adalah Allah. Tetapi, tautologi "Allah adalah Allah" merupakan sebuah afirmasi logis yang sebenarnya menyangkal Allah Trinitaris sebagai Allah yang hidup. Substansi ilahi tidak mengandung ontologi hakekat diri Allah sebagai komunitas. Zizioulas menuturkan, "It would be unthinkable to speak of the "one God" before speaking of the God who is "communion," that is to say, of the Holy Trinity."18 Dengan demikian, Zizioulas meyakini bahwa di dalam diri Allah pun Pribadi melampaui substansi.

Zizioulas menjelaskan bahwa Bapa, Putera, dan Roh Kudus adalah "nama" yang menandakan identitas personal masing-masing Pribadi sebagai yang primer-dan-absolut, unik-dan-tak-tergantikan. ${ }^{19}$ Bapa adalah "Yang Lain" bagi Putera dan Roh Kudus; demikian pula Putera bagi Bapa dan Roh Kudus, dan Roh Kudus bagi Bapa dan Putera. Dengan identitas personal masing-masing, setiap Pribadi bergerak ke luar diri-Nya, ke arah kedua Pribadi yang lain untuk berelasi, berkomunitas. Gerak ini menampakkan karakter ekstasis-hipostasis Pribadi.

Selanjutnya Zizioulas menyatakan bahwa Bapa adalah the cause, penyebab keberadaan kedua Pribadi yang lain, yakni Putera dan Roh Kudus. Bagi banyak orang, gagasan ini akan membentuk gambar hirarkis Allah Trinitaris dan berpotensi memberikan legitimasi bagi ketidaksetaraan relasi dan pemaksaan kekuasan oleh yang satu kepada yang lain. Zizioulas berargumen bahwa gagasan Bapa sebagai the cause memang akan nampak hirarkis bagi orang yang memahami causa dalam dimensi waktu. Maka, bagi orang itu, Pribadi Bapa lebih dulu ada dari pada Pribadi Putera dan Pribadi Roh Kudus. Belajar dari para Bapa Gereja Kapadokia,

18 John Zizioulas, Being as Communion, p. 17.

19 John Zizioulas, Communion and Otherness, p. 166. 
Zizioulas melepaskan causa dari waktu, menempatkannya di dalam konsep "pribadi," dan mengemukakan penjelasan yang disebutnya timeless causality. ${ }^{20}$

Di dalam gagasan timeless causality, hal yang terutama adalah proses menjadi pribadi, the how of being, bukan what the being is. Dengan karakter hipostasisnya (partikular dan selalu bergerak ke luar diri), pribadi menjadi ada hanya di dalam relasinya dengan pribadi yang lain. Bapa tidak menjadi Pribadi apabila tidak ada Putera dan Roh Kudus; demikian pula Putera tidak menjadi Pribadi tanpa Bapa dan Roh Kudus; Roh Kudus tidak pula menjadi Pribadi tanpa Bapa dan Putera. Zizioulas menjelaskan:

[T]he Father denotes a particular hypostasis which is 'other' while being relational, that is, inconceivable apart from his unity with the 'other' divine persons. The one God and the triune God are thus conceived simultaneously, thanks not to an impersonal relationality or 'Triunity' but to a hypostasis which is both particular and relational. ${ }^{21}$

Jika pemahaman mengenai causa berdasar pada syarat ontologis keberadaan pribadi, dapatkah Pribadi yang lain (Putera atau Roh Kudus) disebut causa? Mengenai hal ini, Zizioulas mengemukakan alasan biblis. Iman Kristiani bersumber dari Kitab Suci, yang memuat tradisi Israel. Di dalam tradisinya, Bangsa Israel mengenali Allah sebagai figur Bapa. ${ }^{22}$ Yesus pun mengajari para murid untuk menyapa Allah dengan nama Bapa (Mat. 6:5-15) dan mengakui bahwa Bapa lebih besar dari-Nya (Yoh. 14:28). Tetapi, pengakuan tersebut merupakan pengakuan Pribadi Putera atas keberadaan dan keberbedaan Pribadi Bapa, sekaligus memperlihatkan relasi cinta di antara kedua Pribadi. ${ }^{23}$ Allah adalah cinta (1Yoh. 4:8), dan cinta Allah adalah eros..$^{24}$ Eros atau cinta sejati dijelaskan

20 John Zizioulas, Communion and Otherness, pp. 113-154.

21 John Zizioulas, Communion and Otherness, p. 137. Penebalan kalimat kedua dilakukan oleh penulis.

22 John Zizioulas, Communion and Otherness, p. 134.

23 John Zizioulas, Communion and Otherness, p. 140.

24 Gereja Ortodoks berkeyakinan bahwa makna eros sebagai cinta yang luhur telah dirusak oleh pemikiran mengenai seksualitas manusia yang melulu biologis. Akibat 
oleh Zizioulas sebagai anugerah yang diberikan oleh pribadi yang satu kepada pribadi yang lain, sebagai afirmasi keunikan pribadi yang lain itu. Cinta sejati mengalahkan ketakutan pada keberbedaan dan kehadiran pribadi yang lain (1Yoh. 4:18). Di dalam cinta sejati terdapat penegasan sekaligus penerimaan identitas personal pribadi yang satu oleh pribadi yang lain. ${ }^{25}$

Eros menjadi inti gerak hipostasis Allah Trinitaris keluar dari DiriNya untuk berkomunitas dengan "yang lain," yakni manusia dan segenap ciptaan-Nya. Manusia adalah pribadi yang lain bagi Allah. Sebagai pribadi, manusia pun memiliki ketiga karakteristik: primer-absolut, ekstasishipostasis, dan unik-tak tergantikan. Sebagai pribadi, manusia tidak dapat dijadikan objek oleh pribadi/Pribadi lain, dengan konsep ideologis atau demi tujuan apapun. Karena keberbedaannya, manusia tak tergantikan oleh pribadi lain apapun, dan dalam kebebasannya ia bergerak keluar dirinya untuk berelasi dengan pribadi-pribadi yang lain. Namun, pribadi manusia berbeda dari Pribadi Allah. Manusia tidak memiliki substansi ilahi di dalam dirinya. Substansi manusia dibentuk oleh dua kondisi natural, yakni kelahiran dan kematian. Pada manusia, substansi mendahului pribadi. ${ }^{26}$

Kisah manusia jatuh ke dalam dosa memuat kesadaran tentang kondisi natural manusia sebagai makhluk yang dapat musnah, a perishable being. Dosa merupakan representasi kerusakan relasi antarpribadi (antarmanusia, dan manusia dengan ciptaan lainnya), dan juga antara pribadi dan Pribadi (manusia dengan Allah). Tanpa relasi, manusia terisolasi. Keadaan tanpa relasi dan terisolasi itulah yang diidentifikasi oleh Zizioulas sebagai kematian kekal. ${ }^{27}$ Jadi, dosa mengantar manusia ke

perusakan makna eros, orang memilih agape sebagai kata untuk cinta sejati atau cinta Allah. Pandangan Gereja Ortodoks mengenai eros sebagai cinta Allah dapat ditemukan di dalam karya Vladimir Moss, Theology of Eros, http://www.orthodox christianbooks.com/books/. Diunduh pada 26 Desember 2013.

25 John Zizioulas, Communion and Otherness, p. 55.

26 John Zizioulas, Communion and Otherness, p. 166.

27 John Zizioulas, Communion and Otherness, pp. 263-264; Being as Communion, p. 78 ff. 
kematian. Namun, Allah Trinitaris berinisiatif membawa manusia kembali ke dalam relasi dengan Diri-Nya. Prakarsa Allah Trinitaris ini terwujud konkret di dalam peristiwa Inkarnasi. Pribadi Putera, Yesus Kristus, hadir di antara dan berelasi dengan orang-orang yang diklasifikasi sebagai pendosa dan-oleh sebab itu-diisolasi oleh masyarakat Israel. Peristiwa salib menyatakan secara tegas kondisi natural atau substansi manusia yang terikat pada kematian kekal: kerusakan, kehancuran, dan kemusnahan. ${ }^{28}$ Peristiwa kebangkitan (badan) menandakan bahwa Allah Trinitaris telah mengatasi kondisi natural manusia itu. Allah mengangkat pribadi manusia, menjadikannya mulia, mengatasi substansi/kondisi naturalnya. Destinasi manusia sebagai pribadi bukan lagi kematian, melainkan kehidupan di dalam komunitas bersama Allah. ${ }^{29}$ Kedua peristiwa ini, menurut Zizioulas, menegaskan bahwa manusia memang berbeda dari Allah, namun ia tak terpisahkan dariNya. ${ }^{30}$

Selanjutnya, Zizioulas merumuskan keterkaitan antara cinta (eros) dan hidup manusia.

Life and love are identified in the person; the person does not die only because it is loved and loves; outside the communion of love the person loses its uniqueness and becomes a being like other beings, a "thing" without absolute "identity" and "name," without a face. Death for a person means ceasing to love and to be loved, ceasing to be unique and unrepeatable, whereas life for the person means the survival of the uniqueness of its hypostasis, which is affirmed and maintained by love. ${ }^{31}$

Cinta diprakarsai oleh Allah Trinitaris, dan cinta itu merupakan ekspresi keunikan, ke-tak-tergantikan, dan kebebasan hipostasis Pribadi Allah. Cinta Allah memulihkan manusia sebagai pribadi yang unik, tak tergantikan, dan juga memiliki kebebasan hipostasis, yakni kebebasan

28 John Zizioulas, Communion and Otherness, pp. 266-269.

29 John Zizioulas, Communion and Otherness, pp. 61-62; 75.

30 John Zizioulas, Communion and Otherness, p. 249.

31 John Zizioulas, Being as Communion, p. 49. 
untuk mencintai dan berkomunitas dengan yang lain. Dicintai dan mencintai adalah inti hidup manusia sebagai pribadi. Tanpa cinta, manusia tidak dapat menjadi pribadi karena padanya tidak ada keunikan, ketak-tergantikan, dan kebebasan hispostasis. Ketiadaan cinta dan segala unsur pribadi itu berarti kematian bagi manusia.

Satu hal penting digarisbawahi oleh Zizioulas adalah bahwa konsep pribadi tidak berasosiasi dengan gagasan kepribadian, personality, yang biasa digunakan sebagai kualitas psikologis atau moral, dan bersifat individual. Pribadi manusia tidak dikenali di dalam sebuah entitas statis individu, melainkan di dalam proses menjadi komunitas. Sebab, sekali lagi, pribadi memiliki karakter ekstasis-hipostasis. Dengan karakter ini, manusia menjadi pribadi yang integral dan tak terpecah, sekaligus transenden, bergerak bebas melampaui batas-batas dirinya untuk berkomunitas dengan Pribadi/pribadi yang lain. ${ }^{32}$ Zizioulas mempertegas pandangannya bahwa manusia tak dapat menjadi Allah sebab demikianlah substansinya, tetapi ia dapat hidup di dalam komunitas dengan Allah, mengalami kehidupan ilahi bersama seluruh ciptaan-Nya; bahkan sesungguhnya manusia diciptakan sebagai imago Trinitatis. Istilah imago Trinitatis dengan sengaja digunakan oleh Zizioulas untuk menegaskan substansi ilahi dan Pribadi Allah Trinitaris. Menjadi imago Trinitatis merupakan kapasitas tertinggi manusia sebagai pribadi. ${ }^{33}$ Menjadi imago Trinitatis, manusia tidak sekadar memikirkan dan mengupayakan kekudusan atau keselamatan individual dirinya, melainkan kekudusan dan keselamatan bersama pribadi-pribadi yang lain; bersama seluruh ciptaan Allah.

Panggilan manusia menjadi imago Trinitatis nyata di dalam peristiwa Kristus. Peristiwa Kristus mengatasi substansi manusiawi, dan memulihkan pribadi manusia. Peristiwa Kristus dialami manusia hanya melalui kelahiran baru dalam Roh. Kelahiran baru merupakan tuntutan bagi pribadi manusia untuk meraih kebebasan absolutnya. Di sini, Zizioulas

32 John Zizioulas, Communion and Otherness, pp. 212-213.

33 John Zizioulas, Communion and Otherness, p. 249. 
memperlihatkan kontras dua kelahiran. Di dalam kondisi natural manusia, atau karena substansi manusiawi, kelahiran berhadap-hadapan dengan kematian. Di dalam peristiwa Kristus, kelahiran terarah ke kehidupan kekal karena Roh Kudus. ${ }^{34}$

Zizioulas pun memperlihatkan gagasan kristologis-pneumatologisnya yang berfondasi biblis. Di dalam kisah kelahiran (Mat. 1:18-20; Luk. 1:35), Kristus menjadi pribadi historis hanya di dalam Roh Kudus. Roh Kudus berperan juga di dalam pengurapan-Nya dan persiapan-Nya sebagai Mesias (Luk. 3:22-4:12). Santo Paulus meyakinkan jemaat di Korintus bahwa pengakuan akan Kristus berasal hanya dari Roh Kudus, dan bahwa Roh pula yang mempersatukan orang-orang beriman, menjadikan mereka Tubuh Kristus, dan memberikan karunia kepada setiap anggotanya (1Kor. 12). Maka, menurut Zizioulas, tidak berlebihan bila dikatakan bahwa Kristus dapat hadir hanya oleh dan bersama Roh Kudus. Artinya, peristiwa Kristus bukan sebuah peristiwa tunggal dan tidak dapat berdiri sendiri, bahkan secara teoritis sekalipun. Peristiwa Kristus merupakan bagian integral dinamika hidup dan gerak Allah Trinitaris. Berbicara mengenai Kristus berarti berbicara mengenai Roh Kudus dan Bapa juga, sebab Inkarnasi terjadi oleh karena peran Roh Kudus, dan Inkarnasi itu sendiri merupakan ekspresi dan realisasi kehendak Bapa. ${ }^{35}$

Dalam konteks pemahaman di atas, baptisan juga merupakan bagian integral dinamika Allah Trinitaris. Roh Kudus, daya pemberi hidup, mem-buka eksistensi manusia untuk menjadi pribadi sekaligus menjadi komu-nitas, sebagaimana Allah Trinitaris adalah Pribadi yang berkomunitas. ${ }^{36}$ Tiga hal penting ditegaskan oleh Zizioulas mengenai baptisan. Pertama, baptisan membebaskan manusia untuk menjadi pribadi, mengikuti Kristus menjadi imago Trinitatis. Kedua, baptisan merupakan tanda bahwa menjadi pribadi bukan prestasi moral manusia, melainkan sebuah proses berkomunitas dengan dunia, sesama manusia,

34 John Zizioulas, Being as Communion, pp. 19, 113.

35 John Zizioulas, Being as Communion, p. 111.

36 John Zizioulas, Communion and Otherness, p. 165. 
dan Allah. Ketiga, menjadi pribadi merupakan sebuah peristiwa komunitas yang tidak dapat diwujudkan secara individual, melainkan secara komunal oleh sebuah realita eklesial. ${ }^{37}$

\section{GEREJA SEBAGAI IMAGO TRINITATIS}

Bagi Zizioulas, realitas eklesial, yakni Gereja, bukan sekadar sebuah institusi. Gereja merupakan "a mode of existence," atau "a way of being [that] is deeply bound to the being of man, to the being of the world, and to the very being of God." 38 Gereja juga memiliki kualitas "pribadi" di dalam dirinya, terutama kualitas hipostasis. Ecclesial hypostasis, demikian Zizioulas menyebutnya, membentuk karakteristik Gereja yang pertama dan terutama: katolik. Kekatolikan mencakup relasi dengan dunia dan di dalam dunia. Relasi itu tidak ditentukan oleh hukum-hukum biologis, seperti ikatanikatan keluarga, suku, dan ras. Kekatolikan melampaui individualisme dan eksklusivisme. Kekatolikan memuat kemampuan mencintai "yang lain" secara inklusif. Kemampuan ini tidak berasal dari kebutuhan moral, melainkan dari eros, cinta yang memungkinkan kelahiran baru oleh Roh Kudus melalui peristiwa Kristus. Mencintai dan berelasi dengan "yang lain," Gereja (dan setiap anggota Gereja), menemukan identitas dirinya yang unik and otentik sebagai image Allah Trinitaris. ${ }^{39}$

Karakteristik Gereja yang kedua ialah ekaristis. Ekaristi, dalam pandangan Zizioulas, "is not only an assembly in one place, that is, a historical realization and manifestation of the eschatological existence of man; it is at the same time also movement, a progress towards this realization." 40 Ekaristi memiliki dua elemen pokok: persekutuan umat dan gerakan; dan keduanya tak terpisahkan. Zizioulas menjelaskannya demikian. Gereja sebagai komunitas eklesial memiliki orientasi eskatologis, yakni kesatuan seluruh ciptaan di dalam Kristus (Yoh. 17). ${ }^{41}$ Di dalam Perayaan Ekaristi,

37 John Zizioulas, Being as Communion, p. 15.

38 John Zizioulas, Being as Communion, p. 15.

39 John Zizioulas, Being as Communion, p. 58; Communion and Otherness, p. 89.

40 John Zizioulas, Being as Communion, p. 61.

41 John Zizioulas, Being as Communion, 147. Pernyataan Zizioulas bahwa orientasi eskatologis Gereja ialah hidup berkomunitas dengan Allah terlihat menarik mengingat 
orang beriman berkumpul sebagai komunitas, mengungkapkan harapan eskatologis akan kesatuan seluruh ciptaan di dalam Kristus, sekaligus menyadari tugas berkelanjutan untuk mewujudkan kesatuan itu. Di dalam Ekaristi, sebutan-sebutan "bapa" atau "saudara" dilepaskan dari ikatan biologis-eksklusif, dan menjadi ungkapan relasi cinta yang membebaskan dan universal. ${ }^{42}$ Sebagai penegasan, Zizioulas mengangkat dua peristiwa perjamuan yang melatarbelakangi Ekaristi, yakni perjamuan Paskah Yahudi dan perjamuan malam terakhir Yesus bersama muridmurid-Nya. Perbedaan di antara kedua peristiwa perjamuan ini seringkali luput dari pandangan umat Kristiani. Perayaan Paskah Yahudi adalah perayaan keluarga Yahudi, yang dihadiri oleh anggota-anggota keluarga yang terikat oleh garis darah dan kebangsaan, sedangkan perjamuan malam terakhir merupakan perayaan orang-orang yang percaya kepada Yesus sebagai Kristus, yang berkumpul sebagai saudara bagi satu sama lain. ${ }^{43}$

Kedua karakteristik, katolik dan ekaristis, merupakan dua tonggak yang saling menopang, memperkokoh identitas Gereja. Dinamika keduanya digambarkan oleh Zizioulas demikian:

The way the catholicity of the Church is revealed in the eucharistic community shows that the ultimate essence of catholicity lies in the transcendence of all divisions in Christ. [...] It covers all areas and all dimensions of existence whether human or cosmic, historical or eschatological, spiritual or material, social or individual, etc. [...] The eucharistic community with its understanding of the eucharist as a meal, with its basic elements being material and not merely spiritual, with its long litanies and supplications in

biasanya orang membangun harapan akan "kehidupan kekal." Dalam hal ini, kita perlu kembali ke keyakinan Zizioulas bahwa kehidupan kekal hanya dialami di dalam kesatuan dengan Pribadi dan pribadi-pribadi yang lain. Ketika komunitas absen, hanya ada kematian bagi pribadi. Menjadikan kesatuan di dalam Kristus sebagai orientasi masa depan Gereja, Zizioulas menegaskan prioritas orang beriman untuk mengupayakan hidup komunitas dan keselamatan bersama, melampaui individualisme dan egosentrisme.

42 John Zizioulas, Being as Communion, p. 60.

43 John Zizioulas, The Eucharistic Community and The World, ed. Luke Ben Tallon (New York: T\&T Clark International, 2011), pp. 3-4. 
which man's everyday material and physical needs find their place etc., constitutes a sign of a "catholic" view of existence in which no dualistic dichotomies can be accepted. ${ }^{44}$

Identitas Gereja ditandai oleh keberbedaan di dalam dirinya, sekaligus kesatuan dan keutuhannya sebagai komunitas. Zizioulas menggambarkan Gereja sebagai tubuh, seperti metafora yang digunakan oleh Paulus (1Kor. 12:12-27). Ia menyebutkan dua macam tubuh, yakni tubuh biologis dan Tubuh Kristus. Tubuh biologis bersubstansi manusiawi dan, oleh karena-nya, dapat punah. Berkat baptisan, berkat ecclesial hypostasis, tubuh biologis menjadi transenden, dibebaskan dari kondisi naturalnya dan menjadi tubuh ekaristis, Tubuh Kristus. ${ }^{45}$

Zizioulas menegaskan bahwa Gereja adalah sebuah realitas kristologis. Identitas Gereja ada di dalam Kristus. "[The Church] is where Christ is." ${ }^{46}$ Mengikuti gerakan Kristus, Gereja menghadirkan diri sebagai kesatuan yang merangkul keberbedaan, dan sebagai komunitas transenden yang mengatasi keterpecahan di dalam dirinya - termasuk keterpecahan natural berdasarkan ras, usia, gender-dan keterpecahan akibat dikotomi antara yang spiritual dan yang material, yang lokal dan yang universal. Gereja bergerak terarah ke keutuhan, kepenuhan, dan totalitas Tubuh Kristus. ${ }^{47}$ Gerakan ini melibatkan pula dunia. Gereja memang melampaui kondisi natural biologis dunia, namun tidak menyangkal keberadaan dunia sebagai "yang lain" bagi dirinya. "[The Church] accepts the biological nature [of the world] but wishes to hypostasize it in a nonbiological way, to endow it with real being, to give it a true ontology, that is, eternal life." 48

Pengenalan akan Allah Trinitaris sebagai Pribadi berkomunitas, dan Gereja sebagai image-Nya, menuntut pembaruan cara hidup Gereja

44 Zizioulas, Being as Communion, p. 162. Penebalan kalimat pertama dibuat oleh penulis.

45 Zizioulas, Being as Communion, pp. 63-64.

46 Zizioulas, Being as Communion, p. 158.

47 Zizioulas, Being as Communion, p. 149.

48 Zizioulas, Being as Communion, p. 63. 
sehari-hari. Secara eksplisit, Zizioulas mengemukakan bahwa pembaruan yang terutama ialah pembaruan struktur dan pelayanan Gereja, termasuk di dalamnya hirarki. Pembaruan struktur di dalam Gereja dimulai dari tindakan menghargai keberbedaan senilai dengan kesatuan. Mengikuti dinamika Allah Trinitaris, Gereja tidak menjadikan keberbedaan sebagai unsur sekunder yang kurang penting dibandingkan dengan kesatuan. ${ }^{49}$ Menempatkan kesatuan di atas keberbedaan sama artinya dengan meng-utamakan substansi di atas pribadi. Ini bertentangan dengan ide teologis yang diuraikan oleh Zizioulas bahwa pribadi melampaui substansi. Gereja, menurut Zizioulas, semestinya menyadari keberbedaan sebagai unsur primordial bagi dirinya. ${ }^{50}$

Berdasarkan hal ini, Zizioulas mengemukakan pendapatnya mengenai Gereja lokal dan Gereja universal. Menurutnya, setiap Gereja lokal adalah Tubuh Kristus yang utuh, komunitas ekaristis yang penuh, yang hadir di suatu tempat tertentu. Sebaliknya, Kristus seutuhnya, dan Gereja yang katolik, berinkarnasi di dalam setiap Gereja lokal, di dalam identitasnya yang otentik. Struktur gerejawi apa pun tak dapat menyangkal ini. ${ }^{51}$ Gereja universal tidak dapat menjadi komunitas tanpa Gerejagereja lokal, yang masing-masing bersifat unik, otonom, tak tergantikan, dan bergerak ke luar dirinya untuk membentuk komunitas. Dengan kehadiran Kristus, setiap Gereja lokal memiliki identitas otentik yang menjadi kekayaan Gereja universal sebagai "a unity in identity." 52 Dalam hal ini, Zizioulas tidak bermaksud mendukung gagasan bahwa Gereja lokal lebih utama dibandingkan Gereja universal. Bersikap konsisten dengan idenya, Zizioulas menggarisbawahi kehadiran simultan keduanya, Gereja universal dan Gereja lokal, yang satu dan yang banyak. "[T]he nature of the eucharist points [...] in that of the simultaneity of both local and universal." 53

49 Zizioulas, Communion and Otherness, p. 145.

50 Zizioulas, Communion and Otherness, p. 146.

51 John Zizioulas, Communion and Otherness, p. 157.

52 John Zizioulas, Communion and Otherness, p. 158.

53 John Zizioulas, Communion and Otherness, p. 133. 
Kesadaran akan nilai keberbedaan bagi Gereja sebagai komunitas katolik-ekaristis juga merupakan sumber pembaruan pelayanan. Pelayanan berkaitan dengan struktur hirarkis di dalam Gereja. Di dalam pengamatan Zizioulas, struktur hirarkis pada umumnya mengusung kesatuan sebagai prioritas utama. Lebih lagi, kesatuan, yang dijadikan prioritas, identik dengan keseragaman dan sentralitas. Oleh sebab itu, struktur hirarkis seringkali dicurigai sebagai ancaman bagi keberbedaan. Pembaruan struktur hirarkis hanya terjadi bila ada kesadaran bersamaterutama para pemegang otoritas hirarkis dan para pelayan-bahwa tidak ada hirarki yang dapat menjunjung kesatuan tanpa secara simultan merangkul bahkan melahirkan keberbedaan. ${ }^{54}$

Selain itu, Zizioulas menyatakan dua kesadaran yang juga penting dimiliki oleh segenap anggota Tubuh Kristus. Kesadaran pertama adalah setiap pelayanan Gereja merupakan sebuah manifestasi dan juga sebuah refleksi mendalam atas pelayanan Kristus di dalam dunia. Di dalam refleksi Jemaat Perdana, pelayanan Kristus mencakup berbagai aspek kehidupan dan fungsi. Oleh karena itu, mereka mengenakan kepada-Nya segala bentuk pelayanan dan menyapa-Nya dengan berbagai nama, seperti rasul (Ibr. 3:1), nabi (Mat. 23:8; Yoh. 13:13), imam (Ibr. 5:6; 8:4; 10:21; 2:17), uskup (1Ptr. 2:25; Ibr. 13;13), dan diakon (Rm. 15:8; Luk. 22:27; Flp. 2:7). Pelayanan yang berbasis kesadaran kristologis ini mengatasi semua kategori prioritas dan keterpecahan pelayanan yang mungkin disebabkan oleh tahbisan, maupun oleh pembagian-pembagian tugas dan area pelayanan. ${ }^{55}$

Kesadaran yang kedua berpautan dengan komunitas sebagai konteks pelayanan. Pernyataan tegas Zizioulas berbunyi demikian: "[T]here is no ministry that can stand outside or above the community. [...] There is no charisma that can be possessed [or conceived, or operated] individually. [...] There is no ministry in catholic Church that can exist in absoluto." 56 Tahbisan seorang pelayan, menurut Zizioulas, berpotensi

54 John Zizioulas, Communion and Otherness, p. 146.

55 John Zizioulas, Being as Communion, p. 163.

56 John Zizioulas, Being as Communion, pp. 164, 166. 
menjadi sumber keterpecahan pelayanan ketika tahbisan itu menjadi posesi individual si pelayan, dan diterima sebagai tanda penempatan dirinya di luar dan/atau lebih tinggi dari komunitas. Tahbisan pelayan di dalam konteks komunitas katolik-ekaristis membawa implikasi bahwa meterai Roh Kudus yang diberikan tidak berlaku di luar relasi eksistensial si pelayan dengan komunitas yang dilayaninya. Tanpa relasi mendalam antara pelayan dan komunitasnya, pelayanan Gereja bergerak pasti menuju kematian. ${ }^{57}$

Hal terakhir yang penulis dapat kemukakan pada bagian ini ialah dimensi kosmologis di dalam gagasan Zizioulas mengenai Allah Trinitaris.

The Church is nothing other than the work of the economic Trinity applied to us and through us and together with us to the whole cosmos, an image of the Trinity and a foretaste of the eschata, when the whole world will become a movement back to the one God, the Father (1Cor. 15:24) from whom everything, even the persons of the Trinity in their eternal being, comes forth. ${ }^{58}$

Bertanggungjawab atas alam semesta dan segenap isinya merupakan bagian dari kualitas diri komunitas katolik-ekaristis, setiap orang yang menjadi anggotanya, dan juga setiap manusia yang dengannya Gereja berelasi. Allah Trinitaris tidak hanya mengatasi keadaan natural kita manusia, melainkan juga manusia dan segenap makhluk ciptaan yang lain. Manusia diundang untuk berkomunitas dengan makhluk ciptaan lainnya dan dipanggil untuk membawa seluruh ciptaan ke dalam hidup berkomunitas bersama Allah supaya setiap makhluk dibebaskan dari kematian kekal, dan supaya nampak jelas keberadaan dan keberbedaannya masing-masing. ${ }^{59}$ Keengganan manusia untuk berkomunitas dengan seluruh ciptaan Allah menghasilkan chaos, kehancuran, dan kematian bagi keduanya.

57 John Zizioulas, Being as Communion, p. 165.

58 John Zizioulas, Communion and Otherness, p. 149.

59 John Zizioulas, Communion and Otherness, p. 95. 


\section{PENUTUP}

Dari seluruh uraian, ada sebuah garis dasar gambar Allah Trinitaris yang digoreskan oleh Zizioulas bagi kita: "The trinity is not a matter for academic speculation, but for personal relationship." ${ }^{60}$ Penulis membayangkan kesulitan yang kita (umat beriman, klerus maupun awam) hadapi untuk memahami, berelasi dengan, dan menjadi image Allah Trinitaris pada zaman ini. Paus Fransiskus, di dalam Evangelii Gaudium, menyatakan bahwa ketika jejaring dan sarana komunikasi berkembang sedemikian pesat dan canggih, kita semakin mengalami tantangan di dalam menemukan dan berbagi kehidupan dengan yang lain, berjumpa dan bercengkerama, merangkul dan mendukung satu sama lain, melibatkan diri di dalam persaudaraan sejati, solidaritas, dan peziarahan bersama terutama ketika kekacauan terjadi. Banyak orang Kristiani yang menjauhkan diri dari orang-orang lain dan menikmati ruang privatnya, menyangkal dimensi sosial Injil. Sebagian orang Kristiani mengingini spiritualitas Kristus yang sejati tetapi tanpa jalan-jalan inkarnasi dan salib; mengingini relasi interpersonal yang ditawarkan/disediakan oleh sarana super canggih, oleh layar dan sistem-sistem yang dapat dihidupkan dan dimatikan sekehendak mereka. Kebanyakan dari kita tidak menyadari bahwa isolasi diri merupakan sebuah versi "immanentism," yang menutup ruang bagi yang lain, terutama bagi Allah. ${ }^{61}$

Segala kecenderungan, keinginan, dan ketidaksadaran tersebut melekat pada substansi manusiawi kita. Bagaimanapun, oleh baptisan kita sudah mengalami kelahiran baru, menjadi pribadi yang bergerak secara ekstasis-hipostasis, mengikuti gerak Kristus, mengatasi kondisi natural manusiawi kita. Bagaimana pun, "[t]rue faith in the incarnate Son of God is inseparable from self-giving, from membership in the community, from service, from reconciliation with others. The Son of God, by becoming flesh, summoned us to the revolution of tenderness." 62

60 John Zizioulas, Communion and Otherness, p. 95.

61 Pope Francis, Evangelii Gaudium, art. 88, 89.

62 Pope Francis, Evangelii Gaudium, art. 88. 
Revolusi ini merupakan pembaruan cara hidup kita masing-masing, dan cara hidup kita sebagai komunitas katolik-ekaristis. Termasuk di dalamnya ialah struktur dan kepemimpinan hirarkis, semua pelayanan yang kita lakukan, relasi antara pelayan tertahbis dan umat, relasi dengan masyarakat dunia, juga dengan segenap ciptaan Allah.

\section{DAFTAR RUJUKAN}

Francis, Pope. Apostolic Exhoration on the Proclamation of the Gospel on Today's World Evangelii Gaudium. 24 November 2013. http://www. vatican.va/evangelii-gaudium/en/. Diunduh pada 3 Maret 2014.

Kärkkäinen, Veli-Matti, ed. The Trinity: Global Perspectives. Louisville London: Westminster John Knox Press, 2007.

Moss, Vladimir. Theology of Eros. http:// www.orthodoxchristian books.com/ books/. Diunduh pada 26 Desember 2013.

Wilks, John G.F. “The Trinitarian Ontology of John Zizioulas." Dalam Vex evangelica 25 (1995): 63-88. www.biblicalstudies.org.uk/pdf/ vox/vol25/ zizioulas_wilks.pdf. Diunduh 16 Juli 2014.

Zizioulas, John. Being as Communion: Studies in Personhood and the Church. Crestwood, NY: St. Vladimir's Seminary Press, 1985. . Communion and Otherness: Further Studies in Personhood and the Church, ed. Paul McPartlan. New York: T\&T Clark International, 2006.

. The Eucharistic Community and The World, ed. Luke Ben Tallon. New York: T\&T Clark International, 2011. 